\title{
Differential in vitro and in vivo effect of barley cysteine and serine protease inhibitors on phytopathogenic microorganisms
}

\author{
Laura Carrillo $^{\mathrm{a}}$, Ignacio Herrero ${ }^{\mathrm{a}}$, Inés Cambra ${ }^{\mathrm{a}}$, Rosa Sánchez-Monge ${ }^{\mathrm{b}}$, Isabel Diaz ${ }^{\mathrm{a}}$, Manuel Martinez ${ }^{\mathrm{a}}$ \\ ${ }^{a}$ Centro de Biotecnología y Genómica de Plantas (UPM-INIA), Campus Montegancedo, Universidad Politécnica de Madrid, Autovía M40 (Km 38), \\ 28223-Pozuelo de Alarcón, Madrid, Spain \\ ${ }^{\mathrm{b}}$ Unidad de Bioquímica, Departamento de Biotecnologia, E.T.S. Ingenieros Agrónomos, Universidad Politécnica de Madrid, Ciudad Universitaria, 28040-Madrid, Spain
}

Keywords:

Cysteine protease inhibitor

Serine protease inhibitor

Barley

Plant pathogen

Transgenic plant

\begin{abstract}
A B S T R A C T
Protease inhibitors from plants have been involved in defence mechanisms against pests and pathogens. Phytocystatins and trypsin/ $\alpha$-amylase inhibitors are two of the best characterized protease inhibitor families in plants. In barley, thirteen cystatins (HvCPI-1 to 13) and the BTI-CMe trypsin inhibitor have been previously studied. Their capacity to inhibit pest digestive proteases, and the negative in vivo effect caused by plants expressing these inhibitors on pests support the defence function of these proteins. Barley cystatins are also able to inhibit in vitro fungal growth. However, the antifungal effect of these inhibitors in vivo had not been previously tested. Moreover, their in vitro and in vivo effect on plant pathogenous bacteria is still unknown. In order to obtain new insights on this feature, in vitro assays were made against different bacterial and fungal pathogens of plants using the trypsin inhibitor BTI-CMe and the thirteen barley cystatins. Most barley cystatins and the BTI-CMe inhibitor were able to inhibit mycelial growth but no bacterial growth. Transgenic Arabidopsis plants independently expressing the BTI-CMe inhibitor and the cystatin HvCPI- 6 were tested against the same bacterial and fungal pathogens. Neither the HvCPI-6 expressing transgenic plants nor the BTI-CMe ones were more resistant to plant pathogen fungi and bacteria than control Arabidopsis plants. The differences observed between the in vitro and in planta assays against phytopathogenic fungi are discussed.
\end{abstract}

\section{Introduction}

Plant defence against pathogens is a complex process that involves the activation or repression of different signalling pathways leading to the overexpression of target genes with defence properties. One of the main groups of proteins induced after plant pathogen exposition corresponds to the protease inhibitors. These proteins are mainly located in seeds or tubers and are induced in vegetative organs as leaves or roots. Two functions have been related to these proteins: i) regulation of endogenous plant proteases; and ii) inhibition of exogenous proteases from arthropod pests and phytopathogenous microorganisms [1].

Formerly, protease inhibitors were grouped according to the kind of protease inhibited. Then, they were classified as cysteine,

Abbreviations: PhyCys, plant cystatins; $\mathrm{ORF}$, open reading frame; $\mathrm{EC}_{50}$, effective concentration for $50 \%$ inhibition; BTI, barley trypsin inhibitor; $\mathrm{CPI}$, cystatin protease inhibitor. serine, aspartic, and metalloprotease inhibitors [2]. However, several homologous inhibitors are able to inhibit different kind of proteases and they are now classified in function of their sequence similarities and tridimensional structures [3]. Two of the most abundant plant protease inhibitors are the cystatins, family 125 , that are cysteine protease inhibitors, and the cereal trypsin/ $\alpha$-amylase inhibitors, family I6 $[4,5]$.

Plant cystatins (PhyCys) are plant proteinaceous inhibitors of cysteine proteases of the papain C1A family integrated in an independent subfamily on the cystatin phylogenetic tree [6,7]. The cystatin inhibitory mechanism is produced by a tight and reversible interaction with their target enzymes. It involves a tripartite wedge formed by the partially flexible N-terminus containing a glycine residue and two hairpin loops carrying a conserved QxVxG motif and a tryptophan residue, respectively. Most PhyCys are small proteins with a molecular mass in the 12-16 kDa range, but there are some with a molecular weight of $23 \mathrm{kDa}$. These PhyCys have a carboxy-terminal extension which has been involved in the inhibition of a second family of cysteine proteases, the C13 legumain peptidases $[7,8]$. From a functional viewpoint, PhyCys have been implicated in regulation of the protein turn-over and as 
defence proteins [4]. The defence role has been inferred from: i) the ability of PhyCys to inhibit digestive proteases from herbivorous arthropods in vitro, in artificial diets as well as by bioassays on transgenic plants over-expressing PhyCys genes [9-11]; ii) their transcript induction in response to mechanical wounding or methyl-jasmonate [12,13], and; iii) their deleterious effects against phytopathogenic fungi and viruses [14-16].

The implications of Phycys in defence against fungal plant pathogens are supported by a high number of PhyCys genes with antifungal in vitro activity [16-20]. However, the mechanism of inhibition is still not clear. According with a previous report, the inhibition of Botrytis cinerea growth by the barley cystatin HvCPI-1 is not associated with its cysteine protease inhibitory properties and correlates with the absence of intra- and extra-cysteine protease activity in this fungus [15]. Alternatively, it was reported an inhibitory effect of the tarocystatin on Sclerotium rofsii cysteine proteases [21]. At this point, it is unknown how cystatins inhibit fungal growth. Furthermore, neither are evidences on the effect of PhyCys on the growth of phytopathogenic fungi in vivo nor in the in vitro and in vivo growth of plant pathogenous bacteria.

On the other hand, the plant family of the cereal trypsin/ $\alpha$-amylase inhibitors is formed by proteins that accumulate in the seed [5]. Their members can be classified as trypsin inhibitors, $\alpha$-amylase inhibitors, and dual trypsin/ $\alpha$-amylase inhibitors [22]. Three different roles have been attributed to the family I6 inhibitors: i) regulators of seed germination; ii) storage proteins, and iii) defence proteins. Their role as defence proteins is supported by their specificity against amylases and trypsins from insect pests $[23,24]$.

The defence function would be also related to fight against phytopathogenic microorganisms. The implication of trypsin and chymotrypsin inhibitors on fungal and bacterial growth inhibition has been previously reported [25-28]. Among the family I6 inhibitors, the $14 \mathrm{kDa}$ protein from maize seed was able to inhibit spore germination and mycelial growth of nine different plant pathogen fungi [29].

In barley, the complete family of cystatins has been previously characterized. Thirteen cystatins have been described and their evolutionary relations with their target proteases analyzed $[7,30]$. These cystatins have shown different gene structure, variations in the mRNA expression patterns and subcelullar location, and important changes in the deduced amino acid sequences affecting their inhibitory properties $[17,31,32]$. Regarding to defence, the barley cystatins HvCPI-1 to 7 have been tested against the phytopathogenic fungi Fusarium oxysporum and B. cinerea. Likewise, Arabidopsis and maize plants have been transformed with the HvCPI-6 cystatin and their partial resistance against acari and aphids characterized $[11,33]$.

The most characterized 16 trypsin inhibitor in barley is the Itr1 gene encoding the protein BTI-CMe, which has been putatively involved in plant defence. This gene is specifically expressed in the barley endosperm and the purified protein BTI-CMe has been shown to be active in vitro against insect trypsin proteases [23]. Likewise, transgenic rice, wheat and tobacco plants expressing this protein were tested against the performance of several herbivorous pests showing a negative impact on their performance [34-36].

In this study we analyze the in vitro antifungal capability of the thirteen barley cystatins (HvCPI- 1 to HvCPI-13) and the barley BTICMe inhibitor against three important phytopathogenic fungi, Magnaporthe grisea, Plectosphaerella cucumerina and F. oxysporum, and two plant pathogen bacteria, Dickeya dadantii and Pseudomonas syringae. Likewise, we construct Arabidopsis plants expressing the trypsin inhibitor BTI-CMe. These plants and transgenic Arabidopsis plants expressing the HvCPI-6 cystatin were tested to know the resistance to the same fungi and bacteria.

\section{Results}

\subsection{Identification of C1A cysteine peptidases and trypsins in selected pathogen fungi and bacteria}

Bioinformatics searches were done to find putative C1A cysteine proteases and $\mathrm{S} 1$ trypsins in the selected microorganisms. The genomic sequences of the fungi $M$. grisea and several Fusarium species as well as that of the bacteria $D$. dadantii and different $P$. syringae patovars are available in the web [37-40]. The necrotrophic fungus $P$. cucumerina has not been still sequenced but several gene sequences are available in the databanks. From these searches, we found that there are not $\mathrm{C} 1 \mathrm{~A}$ protein sequences in the selected fungi, which is consistently with extensive searches in databanks in which we only found $\mathrm{C} 1 \mathrm{~A}$ sequences in the fungi Podospora anserina and Chaelomium globosum. Trypsins were also absent in the genome of $M$. grisea whereas Fusarium species have one trypsin gene. In contrast, we found both, one $\mathrm{C} 1 \mathrm{~A}$ protein and three trypsin genes in both $D$. dadantii and $P$. syringae bacteria.

\subsection{Inhibitory in vitro activity of barley cysteine and serine protease inhibitors on phytopathogenic microorganisms' growth}

We have previously reported the toxic effects of seven barley cystatins (HvCPI-1 to HvCPI-7) exerted on the fungal growth [17]. To complete this study, we analyzed the antifungal properties of the barley cystatins HvCPI- 8 to HvCPI-13 and the serine protease inhibitor BTI-CMe against $F$. oxysporum. Besides, we tested the growth inhibition exerted by the entire barley cystatin family and the BTI-CMe protein on the phytopathogenic fungi $P$. cucumerina and $M$. grisea. The antifungal dose of each protein was quantified by adding increasing amounts of each inhibitor to the fungal culture medium. The effective concentration for 50\% growth inhibition $\left(E C_{50}\right)$ was calculated for each case (Table 1$)$. Most of the barley cystatins and the trypsin inhibitor BTI-CMe were able to inhibit the spore germination and the mycelial development of the three fungal species in a similar manner (Fig. 1). Then, there were no morphological differences in the microscopical images obtained from cystatin or BTI-CMe fungal inhibition. However, a varied inhibitory level was observed (Table 1). The in vitro growth of $M$. grisea was strongly inhibited for most cystatins at low concentration values $\left(\mathrm{EC}_{50}<1.5 \mu \mathrm{M}\right)$. The strongest inhibitory effects on $F$. oxysporum mycelium growth were produced by HvCPI-2, -3 and -6 proteins

Table 1

Inhibition of the fungal growth of phytopathogenic fungi by barley cysteine and serine protease inhibitors.

\begin{tabular}{llll}
\hline Inhibitor & \multicolumn{2}{l}{$\mathrm{EC}_{50}(\mu \mathrm{M})^{\mathrm{a}}$} & \\
\cline { 2 - 4 } & M. grisea & P. cucumerina & F. oxysporum \\
\hline HvCPI-1 & 4.51 & 5.97 & 2.14 \\
HvCPI-2 & 5.08 & n.i. & 1.02 \\
HvCPI-3 & 0.89 & 5.25 & 0.99 \\
HvCPI-4 & 1.10 & 1.88 & 2.59 \\
HvCPI-5 & 2.75 & 5.7 & 4.15 \\
HvCPI-6 & 0.18 & 1.17 & 1.09 \\
HvCPI-7 & 0.76 & 4.9 & n.i. \\
HvCPI-8 & 0.85 & 3.55 & 5.33 \\
HvCPI-9 & 0.41 & 5.69 & 5.92 \\
HvCPI-10 & 1.25 & 2.25 & n.i. \\
HvCPI-11 & 0.41 & 0.83 & 6.0 \\
HvCPl-12 & 0.77 & 2.82 & 5.46 \\
HvCPI-13 & 1.34 & 4.8 & 1.56 \\
BTl-CMe & 1.23 & 2.5 & 1.52 \\
\hline
\end{tabular}

n.i. = no inhibitory activity detected at concentrations $\leq 6 \mu \mathrm{M}$.

${ }^{\text {a }}$ Effective $\mu \mathrm{M}$ concentration for $50 \%$ inhibition ( $\mathrm{EC}_{50}$ ) was calculated with three replicates of each experiment. Standard errors were lower than $10 \%$. 
M. grisea

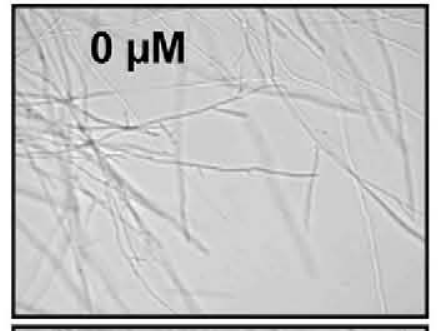

$0.1 \mu \mathrm{M}$
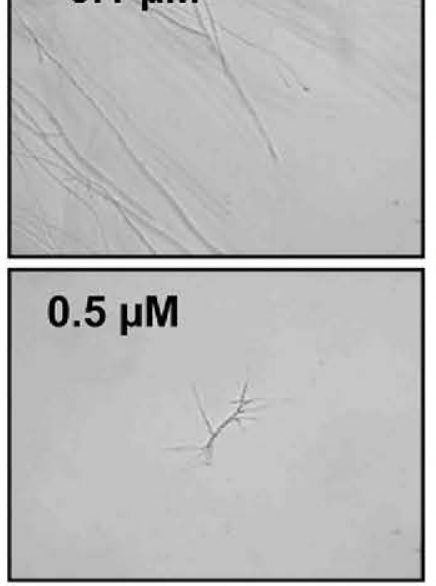

P. cucumerina

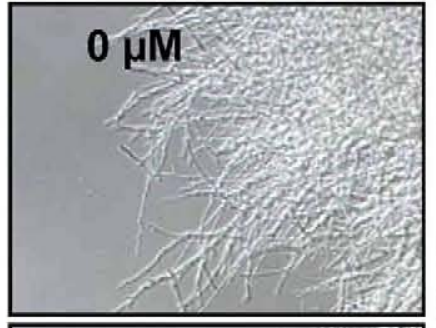

$0.5 \mu \mathrm{M}$

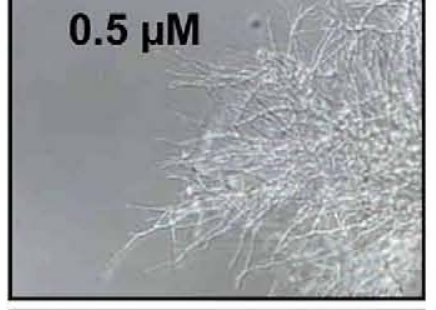

$1.0 \mu \mathrm{M}$

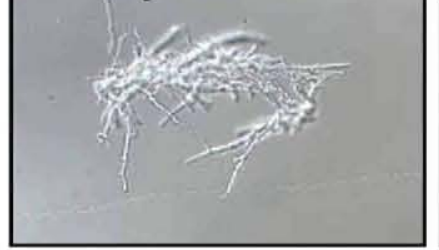

\section{F. oxysporum}
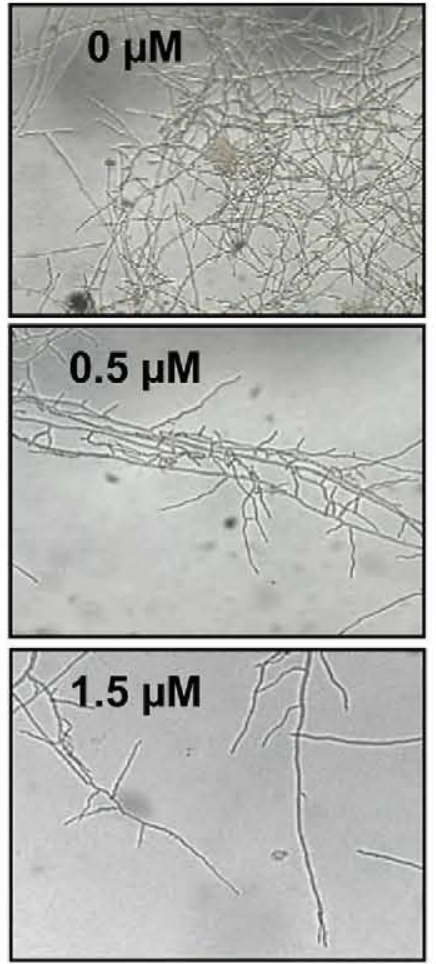

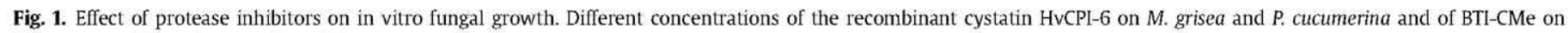
F. oxysporum. Microphotographs at $20 \times$.

$\left(\mathrm{EC}_{50} \approx 1 \mu \mathrm{M}\right)$. The $P$. cucumerina growth was efficiently inhibited by the HvCPI- 6 and -11 cystatins with an $\mathrm{EC}_{50}$ value of $\approx 1 \mu \mathrm{M}$. The recombinant cystatin HvCPI-2 was unable to inhibit the P. cucumerina growth, and cystatins HvCPI-7 and HvCPI-10 did not inhibit $F$. oxysporum growth, at concentrations $\leq 6 \mu \mathrm{M}$. From these data, the HvCPI- 6 cystatin could be considered as the strongest antifungal inhibitor. The BTI-CMe protein was able to inhibit the fungal growth of the three fungi tested at medium concentration $\mathrm{EC}_{50}$ values. No effects were observed when proteins from $E$. coli transformed with the expression vector without insert were used as negative control.

The inhibitory effect of the cysteine and serine protease inhibitors was also tested against phytopathogenic bacteria. In vitro assays were done using different inhibitor concentrations added to suspension cultures of $D$. dadantii or $P$. syringae. In all cases, protein inhibitors were unable to affect the bacterial growth at concentrations below $6 \mu \mathrm{M}$.

\subsection{Molecular characterization of Arabidopsis expressing the BTI-CMe barley serine protease inhibitor}

To further analyze the effect of barley protease inhibitors on phytopathogenic fungi and bacteria, we did in vivo assays with Arabidopsis transgenic plants expressing cysteine and serine protease inhibitors. Plants expressing the strongest antifungal cystatin from barley, the HvCPI-6 protein, were previously characterized in the laboratory [11]. In addition, the Itr1 barley gene encoding the BTI-CMe serine protease inhibitor was stably expressed in Arabidopsis plants. In the transformation process mediated by Agrobacterium tumefaciens, five independent Arabidopsis lines were selected after germinating $\mathrm{T}_{1}$ seeds on kanamycin MS-medium. The presence of the Itr1 gene in the transgenic lines was determined by PCR amplification. All transgenic lines exhibited the expected 534 bp band after electrophoresis of the amplified products, which was absent in the non-transformed plant (Fig. 2A). Their seeds were germinated on selective medium to study segregation rate and to identify homozygous lines in subsequent generations.

The expression of the Itr1 gene in leaves of the transgenic Arabidopsis $\mathrm{T}_{2}$ homozygous lines (1.1, 3.4, 5.6, 7.2 and 8.9) and control leaves ( $\mathrm{Col}-0)$ was analyzed by real-time quantitative RT-PCR using specific primers, and the content of Itr1 mRNA was normalized to Arabidopsis ubiquitin transcript levels. Strong differences in the expression of the serine protease inhibitor among the different transgenic lines were observed (Fig. 2B), with a very low level of transcripts in the 1.1 line. No transcripts were found in the RNA isolated from non-transformed Col-0 leaves. The BTI-CMe expression in the transgenic lines was also studied by assaying its in vitro inhibitory activity against commercial trypsin. Results were quantified by the decrease amount of Z-L-R-AMC hydrolyzed by trypsin and expressed as the percentage of inhibitory enzyme activity. All protein extracts prepared from transgenic lines showed inhibitory activity over the values obtained with protein extracts from the non-transformed control (Fig. 2C). Lines 3.4 and 8.9 were selected for further studies based on their protease inhibitory capability and their high number of seed production.

\subsection{Effects of Arabidopsis transgenic plants on phytopathogenic fungi and bacteria}

Transgenic $\mathrm{T}_{2}$ plants expressing the HvCPI- 6 barley cystatin (lines 5.4 and 9.8 described in [11]) or the BTI-CMe serine protease inhibitor (lines 3.4 and 8.9 in Fig. 2) were used for the evaluation of in vivo effects on fungi and bacteria. 

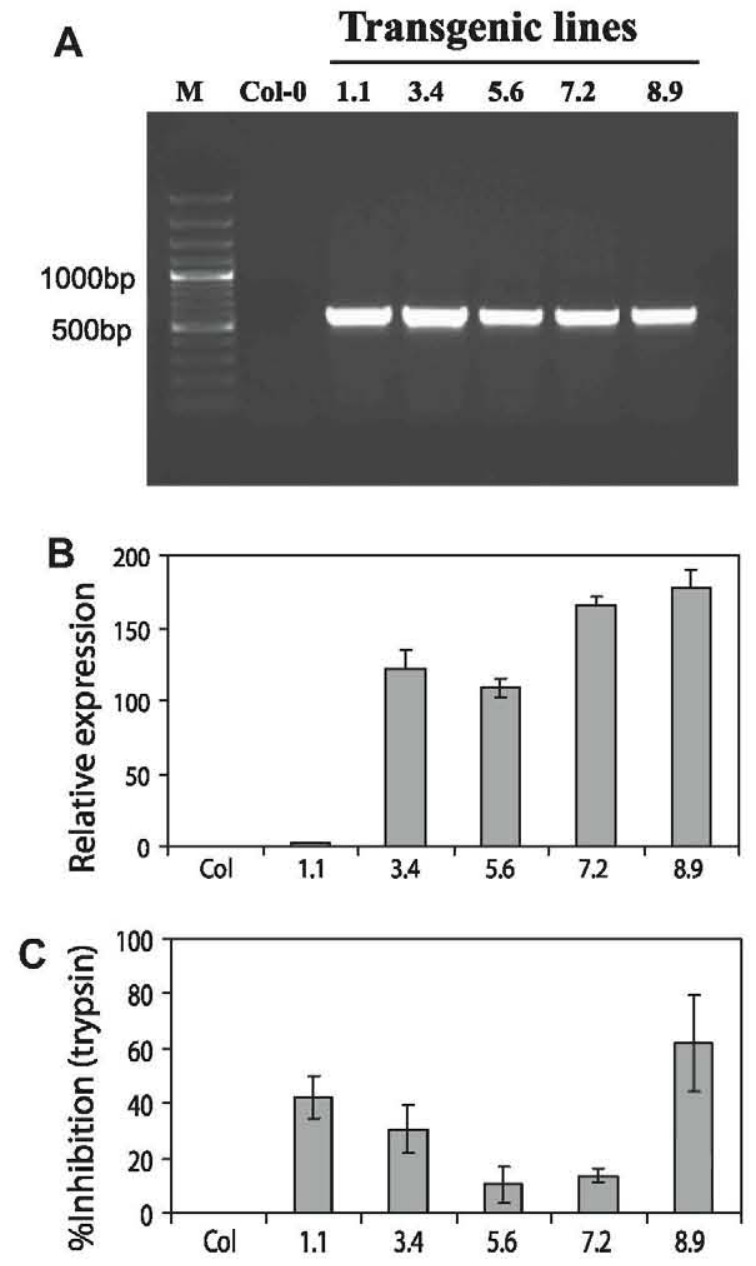

Fig. 2. Molecular analysis of Arabidopsis plants transformed with the Itr1 barley gene encoding the BTI-CMe trypsin inhibitor. (A) PCR analysis of $T_{2}$ transgenic Arabidopsis lines (1.1, 3.4, 5.6, 7.2, and 8.9) and non-transformed control (Col-0) using the sense and antisense primers derived from the CaMV35S promoter and the $3^{\prime}$ region of the Itr 1 gene. M: molecular size marker. (B) Analysis of the expression of the barley Itr1 gene in the $\mathrm{T}_{2}$ transgenic Arabidopsis lines and non-transformed control $(\mathrm{Col}-0)$ by real-time quantitative PCR. Values expressed as the relative mRNA contents of barley Itr1 gene were standardized to the Arabidopsis ubiquitin gene expression. (C) Inhibitory activity of protein extracts from $\mathrm{T}_{2}$ transgenic Arabidopsis lines (20 $\mu \mathrm{g}$ ) against trypsin (100 $\mathrm{ng}$ ) using Z-L-R-AMC as substrate. Data values expressed the relative inhibition of the trypsin activity and are mean values of three independent replicates.

The phytopathogenic fungus $F$. oxysporum enters in the plant by the roots. Its rapid diffusion in the plant leads us to evaluate transgene effects using plants grew in plate to homogenize plant growth conditions. Similar in plate assays were performed as a first approach to test the fungal effect of $P$. cucumerina on Arabidopsis transgenic and non-transgenic plants. The growth of all Arabidopsis lines was retarded after being sprayed and transformed and control plants presented similar chlorotic symptoms for both fungi (Fig. $3 \mathrm{~A}$ ). The weight of the control and the sprayed plants 10 days after inoculation showed a reduction of about $50 \%$ in comparison to the control non sprayed plants of the same lines (Fig. 3B).

Additionally, for $M$. grisea and P. cucumerina we performed in soil plant assays to elucidate the resistance of the transgenic plants against fungal attack. Control and transformed plants were sprayed with fungal spores. Phenotypically disease symptoms were observed 15 and 10 days post-inoculation for $M$. grisea and $P$. cucumerina, respectively (Fig. 4A). Chlorotic and necrotic lesions were present in transformed and non-transformed plants for both fungi, although necrotic lesions were less evident in plants expressing the barley protein HvCPI-6 after $M$. grisea inoculation. When the damaged area was quantified, no differences were found between control and transformed plants (Fig. 4B). No damage was observed in transformed and non-transformed plants sprayed with mock solutions.

Protein extracts of transformed and non-transformed plants were used to test in vitro the inhibition of fungal growth. Proteins from Arabidopsis control plants were able to retard the growth of F. oxysporum, $M$. grisea and $P$. cucumerina. When protein extracts were enriched with the HvCPI-6 cystatin or the BTI-CMe trypsin inhibitor, no differences were observed in comparison to the control extracts from non-transformed isogenic lines (Fig. 4C).

The in vitro and in vivo differential responses observed for the barley protease inhibitors against phytopathogenic fungi lead us to test the resistance against phytopathogenic bacteria for transformed plants using similar in soil assays. Leaves of transformed and non-transformed plants were inoculated with $D$. dadantii or $P$. syringae. After two days of inoculation with $D$. dadantii, leaves of all lines tested were almost totally macerated. For $P$. syringae, necrosis was extensively presented in the inoculated leaves from control and transformed lines after four days of inoculation (Fig. 5A). As observed for fungi, no differences were found between transformed and non-transformed plants when the disease rating was quantified (Fig. 5B). No damage was observed in transformed and non-transformed plants inoculated with mock solutions.

\section{Discussion}

Protease inhibitors have been involved in plant defence due to the implication of extracellular proteases from microorganisms in pathogenesis and the digestive role of proteases in herbivorous pests. This protective function is supported by their in vitro inhibition of both the digestive proteases from herbivorous pests and the growth of plant pathogens [41,42]. A potential application of plant protease inhibitors is their use as biotechnological proteins by stable transformation of crops to fight against pests and pathogens. Transgenic plants have been obtained and their partial resistance against herbivorous pests tested [43].

To obtain further insights on the protective role of plant protease inhibitors, we selected the entire family of barley cystatins and the trypsin inhibitor BTI-CMe. These proteins had been previously characterized [5,17,32], and their role as insecticides and acaricides supported by in vitro assays against digestive proteases from insects and acari, and by in vivo assays using transformed plants expressing some of the cystatins and the BTI-CMe protein [10,11,33-36]. However, their inhibitory capacity towards plant bacterial and fungal pathogens had been less characterized. The in vitro inhibition of fungal growth by plant cystatins has been widely reported [15-19,21]. In barley, the HvCPI-1 to -6 proteins were able to inhibit the growth of $B$. cinerea and $F$. oxysporum pathogens $[15,17]$. However, there were no data on the capacity of plant cystatins to retard bacterial growth. Several trypsin inhibitors are also able to inhibit fungal growth [27], but the inhibitory impact of the barley BTI-CMe on bacterial and fungal pathogens is unknown.

The effect of protease inhibitors on plant pathogens would imply the existence of protein targets in the fungal and bacterial species. In bacteria, both $\mathrm{C} 1 \mathrm{~A}$ cysteine proteases and trypsins are present. In contrast, in the fungi there are no $\mathrm{C} 1 \mathrm{~A}$ cysteine proteases and trypsins were not found in the hemibiotroph $M$. grisea. These results would be consistent with the absence of inhibition of fungal growth by cystatins. However, there are a high number of PhyCys genes with antifungal in vitro activity. Thus, the growth inhibition observed in the in vitro assays for the 13 barley cystatins against the three selected fungi will be in accordance with the previously reported data obtained for the inhibition of $B$. cinerea growth by the barley cystatin HvCPI-1. In this study, the conclusion was that 

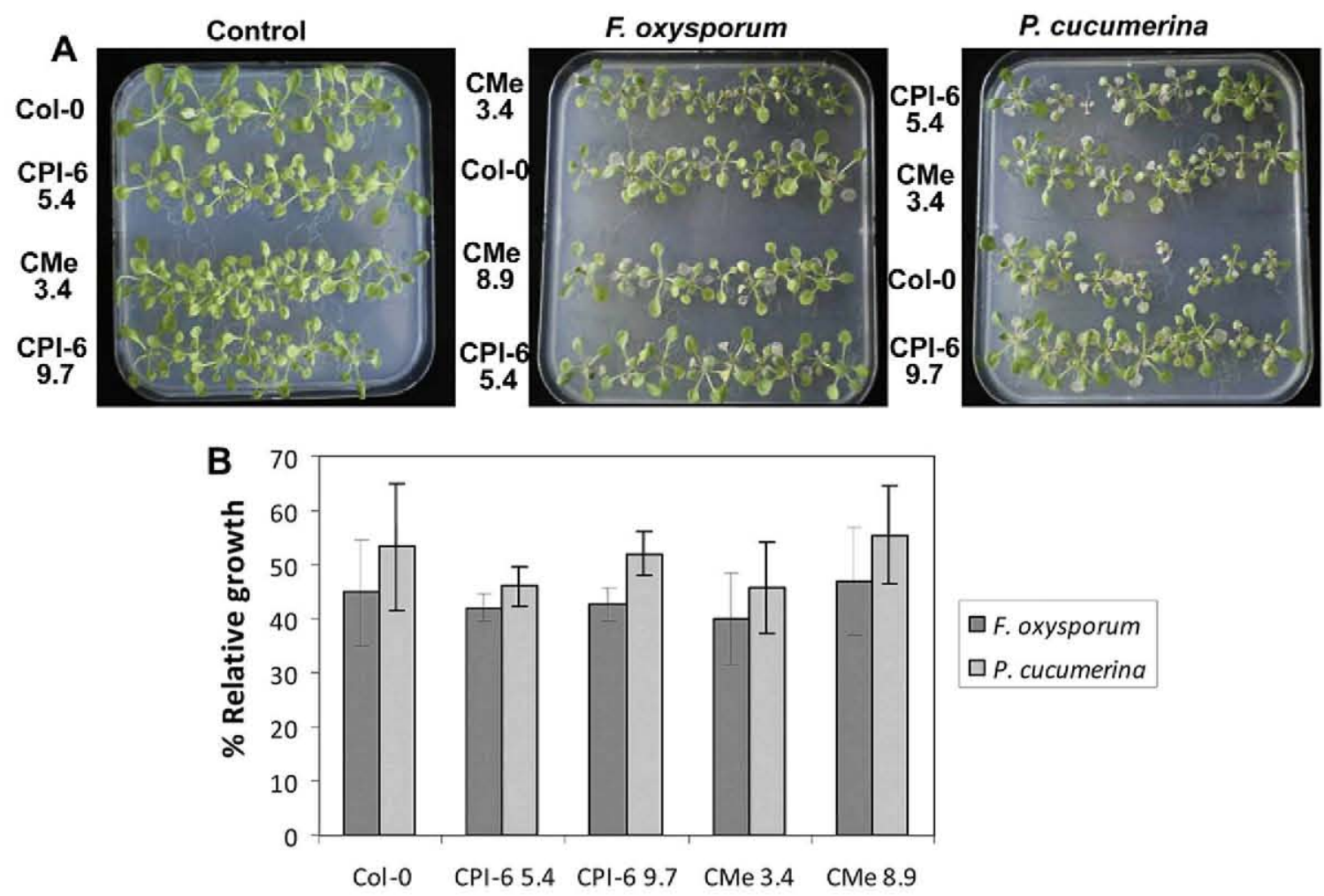

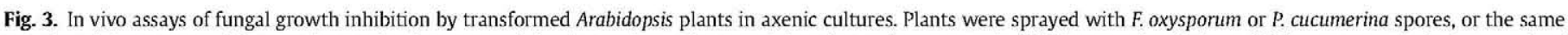

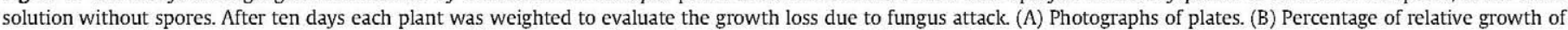

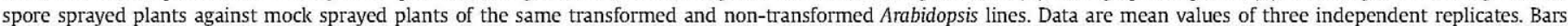
indicate standard errors.

fungal growth inhibition is not associated with their cysteine protease inhibitory properties [15]. The absence of intra- and extracysteine protease activity in this fungus correlates with the absence of $\mathrm{C} 1 \mathrm{~A}$ cysteine proteases in most fungi. Interestingly, most cystatins inhibit the in vitro growth of $M$. grisea stronger than that of $F$. oxysporum and $P$. cucumerina. These results could be related to the different pathogenic mechanism used in the fungal hemibiotrophs (M. grisea) and in the fungal necrotrophs ( $F$. oxysporum and $P$. cucumerina). The trypsin inhibitor BTI-CMe was also able to inhibit fungal growth for both necrotrophs and hemibiotroph fungi, but we cannot decipher the inhibitory mechanism involved in this inhibition.

Growth inhibition of bacterial cultures by barley protease inhibitors would be expected since the selected bacteria have $\mathrm{C} 1 \mathrm{~A}$ cysteine proteases and trypsins. However, neither cystatins nor BTI-CMe inhibits in vitro bacterial growth. Two reasons could explain these results: i) bacterial proteases are not secreted and protease inhibitors cannot enter the bacterial cell; ii) barley inhibitors do not recognize bacterial proteases. Cystatin variability supports this second hypothesis [17,44]. A rapid functional diversification in response to plant pests and pathogens will lead to a wider protease inhibitor repertoire in each plant species. These proteins would be implicated in the defence of the plant to their specific pests and pathogens and could not affect other related plant pathogens. In silico analyses show that bacterial trypsins are possibly secreted, which is also in agreement with the second hypothesis.

Numerous reports had underlined the potential of plant cysteine and serine protease inhibitors for the development of pest and pathogen-resistant transgenic crops $[4,41,43,45]$. However, besides two reports using trypsin inhibitors $[46,47]$, there were no evidences on the effect of single PhyCys on the growth of phytopathogenic fungi and bacteria using transformed plants. In accordance with the in vitro results, we expected that plants transformed with the barley cystatin HvCPI-6 or the trypsin inhibitor BTI-CMe will be more resistant to fungal attack than wild-type Arabidopsis plants. However, the progress of the infection accomplished by fungal pathogens was similar in transformed and non-transformed plants. These results imply: i) a low production of the recombinant protease inhibitor in the plant; or ii) posttranslational modifications of the inhibitors in the plant cell. We have found transcription of both inhibitors in transgenic plants and inhibition of commercial proteases by leaf extracts. Nevertheless, the amount of protein extract necessary to inhibit papain or trypsin was very high suggesting a low concentration of recombinant inhibitors in the plant. The different mechanisms of Phycys involved in the inhibition of in vitro fungal growth and commercial proteases [15] also support protein modifications in the plant cell leading to a failure in fungal growth inhibition whereas their protease inhibitory capacities are not affected. Similar fungal inhibition exerted by protein extracts from Arabidopsis control plants and transformed plants are in agreement with this hypothesis.

In vitro results indicate that PhyCys and BTI-CMe did not affect bacterial growth. However, the unexpected differences between in vitro and in vivo results for fungal growth inhibition lead us to test if possible posttranslational modifications of protease inhibitors in transformed plants could confer them the ability of affecting bacterial growth. The results confirmed that the transgenic plants were also not more resistant to bacterial growth than the nontransformed plants.

In summary, we have obtained novel insights on the interaction of plant protease inhibitors and pathogen microorganisms (Fig. 6). 

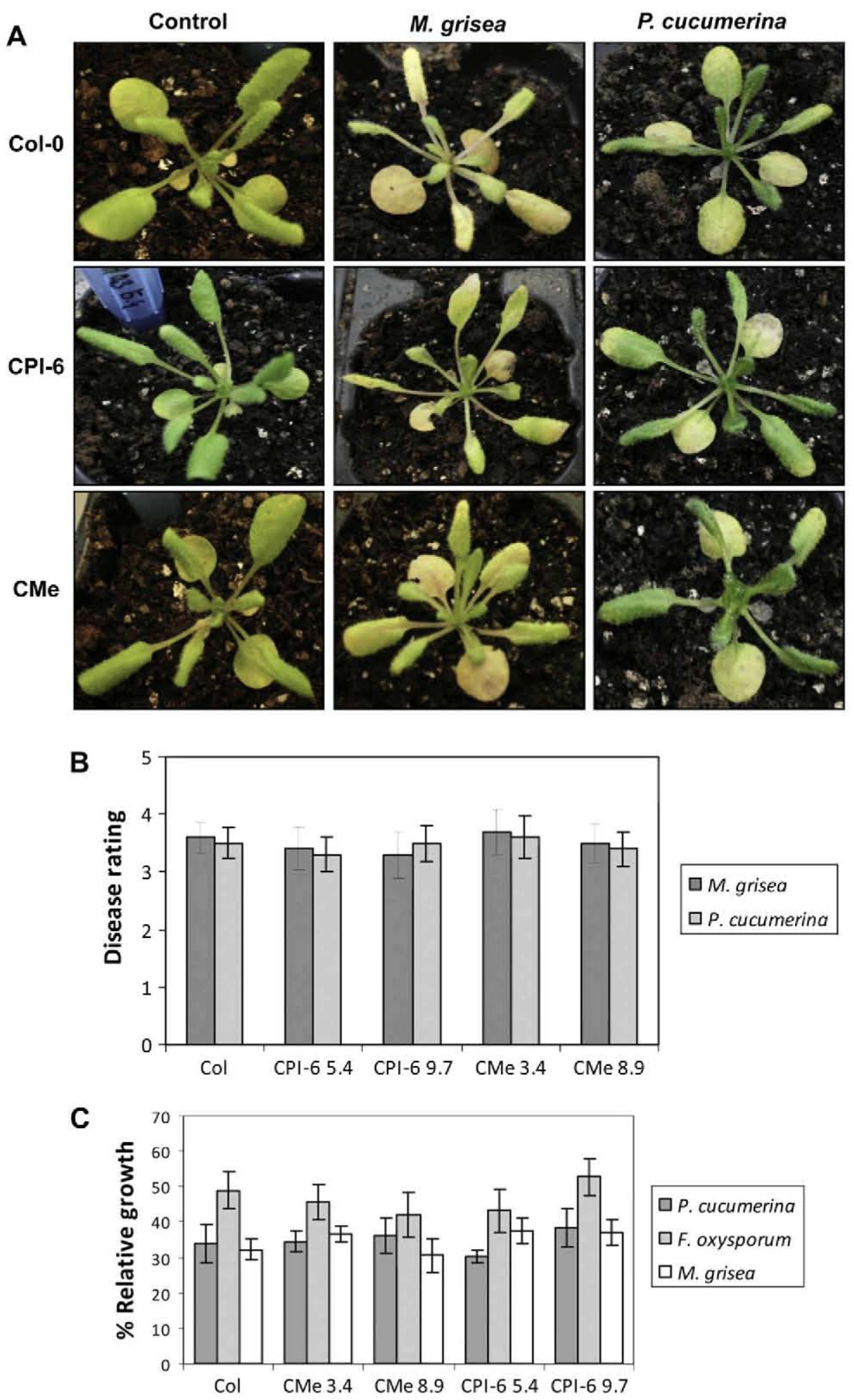

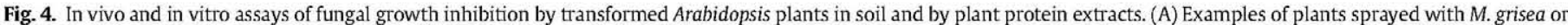

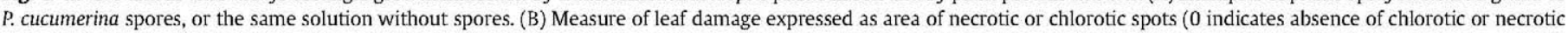

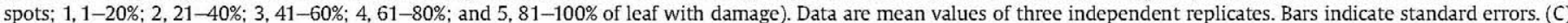

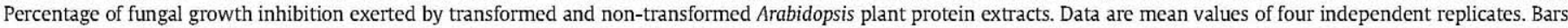
indicate standard errors.

In vitro results demonstrated the inhibition of fungal growth for barley cysteine and serine protease inhibitors, whereas they could not affect bacterial growth. In vivo results reported that Arabidopsis transgenic plants expressing these inhibitors were not more resistant to the fungal and bacterial selected pathogens. Overall, these results indicate that new approaches should be explored to reach the use of protease inhibitors as biotechnological tools involved in plant defence against pests and pathogens. 

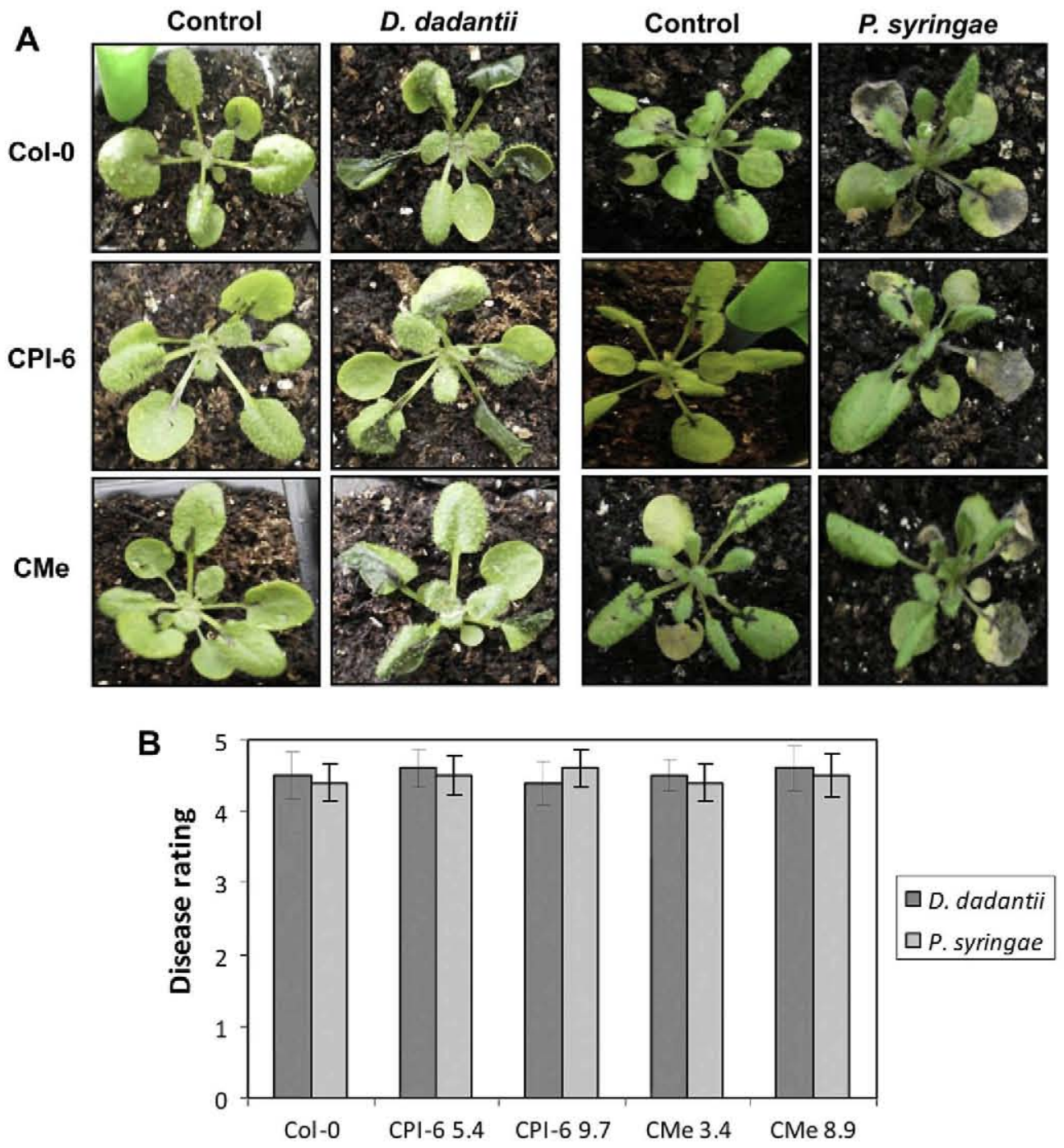

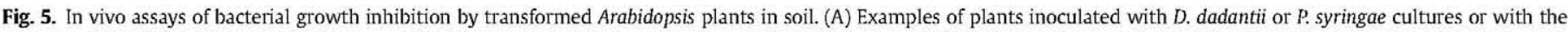

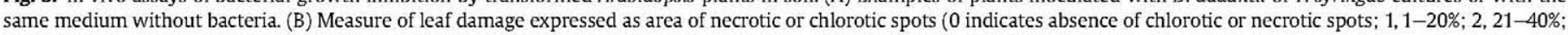
$3,41-60 \% ; 4,61-80 \%$; and 5, 81-100\% of leaf with damage). Data are mean values of three independent replicates. Bars indicate standard errors.

\section{Methods}

\subsection{Databases searches}

BlastP and TBlastN searches for C1A cysteine peptidases and trypsins were performed in publicly available genome databases: the $M$. grisea database [37]; the Fusarium comparative database [38]; the $D$. dadantii 3937 genome project [39]; and the $P$. syringae genome project [40].

Blast searches were made in a recurrent way. First, if available, a complete amino acid fungal or bacterial sequence from databanks corresponding to a protein of the family was used. If not, we used a protein belonging to the family of any other organism. Then, retrieved protein sequences were used to search in the selected bacterial and fungal species. Accession numbers of retrieved sequences are in the Supplementary Table 1.

\subsection{Purification of recombinant cystatins and BTI-CMe}

The cDNA fragments spanning the whole cystatin ORFs, aside from their signal peptide sequences were inserted in frame into the expression vector pRSETB (Invitrogen). The recombinant plasmids for barley HvCPI-1 to HvCPI-13 cystatins were produced and introduced in E. coli as described in Martinez et al. [32]. The fusion proteins with a histidine tail were purified using a His-Bind Resin (Novagen) following the manufacturer's instructions, and purification checked by SDS-PAGE. The trypsin inhibitor BTI-CMe was purified from barley endosperm by high performance liquid chromatography (HPLC) as described in Lázaro et al. [48].

\subsection{In vitro fungal and bacterial growth inhibitory assays}

Fungal strains from the laboratory collection, $F$. oxysporum and $P$. cucumerina, were maintained on potato dextrose agar medium, whereas $M$. grisea was maintained in rice flour medium $\left(20 \mathrm{~g} \mathrm{~L}^{-1}\right.$ rice flour, $2.5 \mathrm{~g} \mathrm{~L}^{-1}$ yeast extract, $15 \mathrm{~g} \mathrm{~L}^{-1}$ agar). Fungal growth inhibitory assays were performed as described by Martinez et al. [15]. Approximately 100 spores of $M$. grisea and 500 spores of $F$. oxysporum or $P$. cucumerina were incubated in $100 \mu \mathrm{L}$ of one-third potato dextrose broth at $28^{\circ} \mathrm{C}$ for $48 \mathrm{~h}$ (F. oxysporum), $72 \mathrm{~h}$ (P. cucumerina) and $96 \mathrm{~h}(\mathrm{M}$. grisea), in agitation and in the absence or presence of different concentrations $(0.1-6 \mu \mathrm{M})$ of the recombinant barley cystatins or BTI-CMe. The incubation was carried out in sterile microtiter plates and fungal growth was monitored by measuring absorbance 


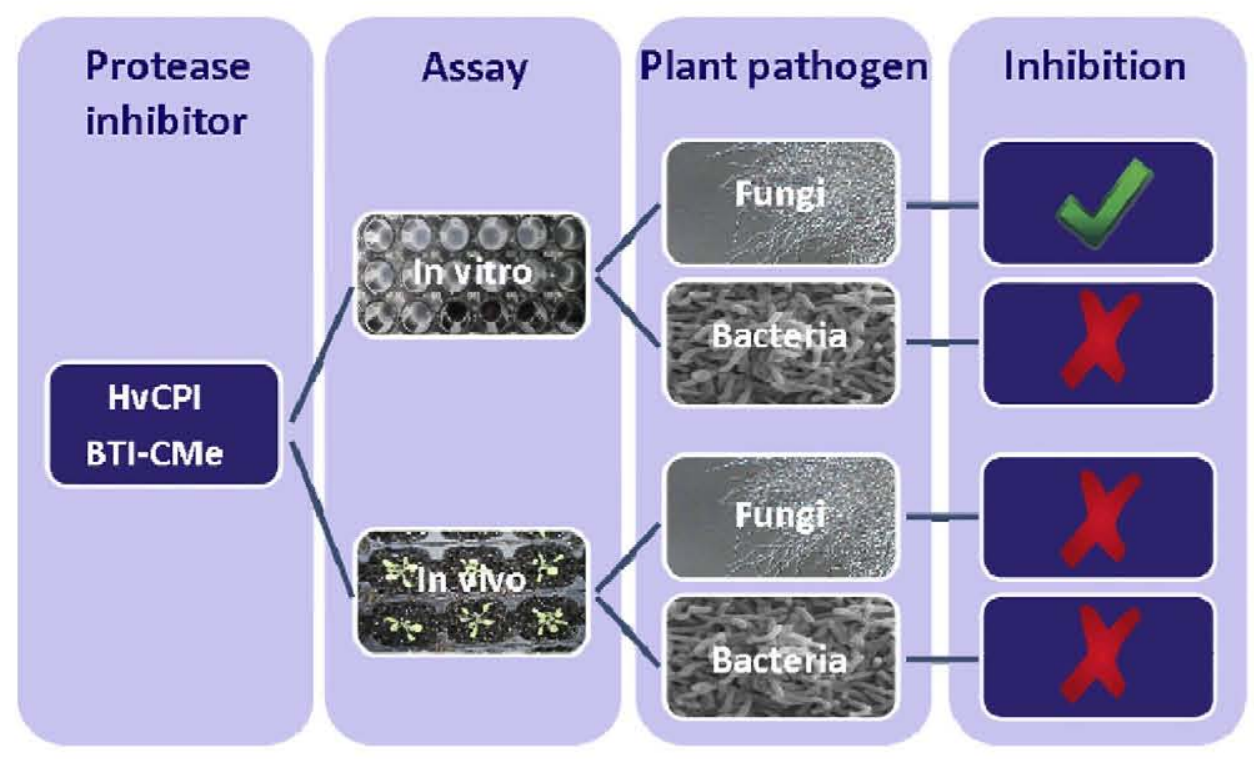

Fig. 6. Schematic representation of the effect of barley protease inhibitors on in vitro and in vivo bacterial and fungal growth.

at $492 \mathrm{~nm}$ and by microscopical observations. Results were expressed as percentage of growth relative to that in the absence of the inhibitory agent and the effective inhibitor concentration for $50 \%$ growth inhibition $\left(\mathrm{EC}_{50}\right)$ for each inhibitor was calculated. Data are mean values of four independent replicates.

Bacterial strains were grown in King's B (KB) medium. The in vitro inhibition assays were performed as described in López-Solanilla et al. [49] in sterile microtiter plates. The inhibitors $(1.5-6 \mu \mathrm{M})$ were incubated with a bacterial concentration of $10^{4} \mathrm{cfu} \mathrm{mL} \mathrm{m}^{-1}$ in $100 \mu \mathrm{L}$ of one-third $\mathrm{KB}$ medium at $28^{\circ} \mathrm{C}$ for $24 \mathrm{~h}$ (D. dadantii) or $48 \mathrm{~h}$ (P. syringae). Bacterial growth was monitored by measuring absorbance at $600 \mathrm{~nm}$. Three independent replicates were made for each assay.

\subsection{Plasmid constructs and plant transformation}

Arabidopsis plants were previously transformed with the ORF of the Icy6 gene without its signal peptide (35S-Icy6-plants) [11]. The ORF of the barley trypsin inhibitor Itr1 gene, encoding BTI-CMe protein, devoid of its signal peptide sequence was inserted between the CaMV35S promoter and the NOS terminator of the binary pROKII vector [50]. The resultant plasmid was used to transform Arabidopsis thaliana (L.) Heyn plants from ecotype Columbia (Col-0) by the Agrobacterium-mediated floral dip method [51]. Seeds from the transformed plants were harvested and plated on MS-medium, containing $50 \mu \mathrm{g} \mathrm{mL}$ kanamycin to select 35S-Itr1-plants.

\subsection{Nucleic acid analysis of transformed plants}

Total DNA was isolated from transformed and control Arabidopsis leaves and tested for the presence of the Itr1 gene by PCR using the primer pairs, ara35S-forward: $5^{\prime}$ - CACTATCCTTCGCAAGACC - $3^{\prime}$ and araBTI-CMe-reverse: $5^{\prime}$ - CGAGGTACCTTACAAGACCACTCCATATCC $3^{\prime}$. The reaction products were separated on $1 \%$ agarose electrophoretic gels.

For real-time quantitative RT-PCR (qRT-PCR) studies, transformed and control leaves of Arabidopsis were collected and frozen into liquid $\mathrm{N}_{2}$ and stored at $-80^{\circ} \mathrm{C}$ until used for RNA extraction. Total RNA was extracted by the phenol/chloroform method, followed by precipitation with $8 \mathrm{M} \mathrm{LiCl}$ [52]. cDNAs were synthesized from $2 \mu \mathrm{g}$ of RNA using the High-capacity cDNA reverse transcription kit (Applied Biosystems) following manufacturer's instructions.
RNAse free DNAse was added to avoid DNA contamination. qRT-PCR analyses were performed for duplicated samples using RNA from different extractions by means of a 7300 Real-Time PCR System (Applied Biosystems) using an SYBR Green detection system. Quantification was standardized to Arabidopsis ubiquitin mRNA levels (At5g25760). The primers used for PCR amplification were:

- qrtBTI-CMe-forward: 5' - TCCTCACCTCGGACATGAAGA - 3';

- qrtBTI-CMe-reverse: 5' - CCCTGCCAAGTTACTACCCCTT - 3';

- AtUbi-forward: 5'-GCTCTTATCAAAGGACCTTCGG-3';

- AtUbi-reverse: 5'-CGAACTTGAGGAGGTTGCAAAG-3'.

\subsection{Inhibitory activity of protein extracts of Arabidopsis plants}

Total protein extracts from leaves were obtained from transformed and control Arabidopsis plants. Leaves were grounded and resuspended in $0.15 \mathrm{M} \mathrm{NaCl}$ sodium phosphate $\mathrm{pH}$ 6.0, 2 mM EDTA for $1 \mathrm{~h}$ at $4{ }^{\circ} \mathrm{C}$. After centrifugation for $15 \mathrm{~min}$ at $10,000 \mathrm{rpm}$, supernatants were recovered and their protein content quantified. Inhibitory activity of plant protein extracts expressing the barley Itr1 gene was in vitro tested against commercial trypsin (EC 3.4.21.4) from Sigma using Z-L-R-AMC (Z-L-Arg-7-amido-4-methylcoumarin) as substrate. Twenty $\mu \mathrm{g}$ of protein extracts were preincubated with $100 \mathrm{ng}$ of trypsin in buffer Tris- $\mathrm{HCl} 0.1 \mathrm{M}, \mathrm{pH} 7.5$ during $10 \mathrm{~min}$. Then, the substrate was added and the mixture incubated $20 \mathrm{~min}$ at $30^{\circ} \mathrm{C}$. Fluorescence was measured with a microplate fluorescence reader (Tecan GeniusPro) using an excitation filter of $365 \mathrm{~nm}$ and an emission filter of $465 \mathrm{~nm}$. Results were expressed as the percentage of inhibition of trypsin activity. Three independent replicates were made.

Inhibition of fungal growth by plant protein extracts was performed as described previously in Section 4.3. Twenty $\mu \mathrm{g}$ of protein extract were used in these assays. Results were expressed as the percentage of inhibition of fungal growth. Four independent replicates were made for each assay.

\subsection{Plate inhibitory assays of transformed Arabidopsis plants against phytopathogenic fungi}

Seeds from Itr 1 and Icy 6 transformed and from non-transformed Arabidopsis plants were grown in square plates at $22^{\circ} \mathrm{C}$ and $8 \mathrm{~h} / 16 \mathrm{~h}$ 
light/dark photoperiod for ten days. Eight control Col-0 plants and three different transgenic lines were placed in each plate. Then, plates were sprayed with $900 \mu \mathrm{L}$ of a solution containing $4 \times 10^{6}$ spores of $F$. oxysporum or $P$. cucumerina, or the same solution without spores. After 10 days each plant was weighted to evaluate the growth loss due to fungus attack. Assays were repeated three times with similar results.

\subsection{Soil inhibitory assays of transformed Arabidopsis plants against phytopathogenic fungi and bacteria}

Seeds from Itr 1 and Icy 6 transformed and from non-transformed Arabidopsis plants were grown in $3.5 \mathrm{~cm}$ diameter pots at $22^{\circ} \mathrm{C}$ and $8 \mathrm{~h} / 16 \mathrm{~h}$ light/dark photoperiod for three weeks. Then, for phytopathogenic fungi assays, 40 plants were sprayed with $12 \mathrm{~mL}$ of $M$. grisea spores at $3.3 \times 10^{5}$ spores. $\mathrm{mL}^{-1}$ and incubated 15 days or $12 \mathrm{~mL}$ of $P$. cucumerina spores at $6 \times 10^{7}$ spores. $\mathrm{mL}^{-1}$ and incubated 10 days. For phytopathogenic bacteria $P$. syringae, $4-5$ leaves per plant were infiltrated with $100 \mu \mathrm{L}$ of a solution containing $4 \times 10^{8} \mathrm{cfu} \mathrm{mL}^{-1}$ using a syringe and incubated four days. For $D$. dadantii, 4-5 leaves per plant were pierced with a needle and then $10 \mu \mathrm{L}$ of a solution containing $4 \times 10^{8} \mathrm{cfu} \mathrm{mL}^{-1}$ were deposited in the holes and incubated two days. Transformed and non-transformed plants were inoculated with solutions without microorganism as controls. All incubations were made at high humidity. The disease rating after the incubation period in inoculated leaves was measured with a scale from 0 to 5 . This scale reflects the percentage of each leaf with chlorotic or necrotic spots. Then, 0 indicates absence of chlorotic or necrotic spots; $1,1-20 \% ; 2$, $21-40 \% ; 3,41-60 \% ; 4,61-80 \%$; and $5,81-100 \%$ of leaf with damage.

\section{Acknowledgements}

The financial support from the Spanish Ministerio de Ciencia e Innovación (project BFU2008-01166), and the Universidad Politécnica de Madrid (Project AL09-PID-09) are gratefully acknowledged.

\section{Appendix. Supplementary data}

Supplementary data related to this article can be found online at doi:10.1016/j.plaphy.2011.03.012.

\section{References}

[1] C.A. Ryan, Protease inhibitors in plants: genes for improving defenses against insects and pathogens, Annu. Rev. Phytopathol. 28 (1990) 425-449.

[2] M. Laskowski Jr., I. Kato, Protein inhibitors of proteinases, Annu. Rev. Biochem. 49 (1980) 593-626.

[3] N.D. Rawlings, A.J. Barrett, A. Bateman, MEROPS: the peptidase database, Nucleic Acids Res. 38 (2010) D227-D233.

[4] M. Benchabane, U. Schlüter, J. Vorster, M.C. Goulet, D. Michaud, Plant cystatins, Biochimie 92 (2010) 1657-1666.

[5] P. Carbonero, F. García-Olmedo, A multigene family of trypsin/ $\alpha$-amylase inhibitors from cereals. in: R. Casey, P.R. Shewry (Eds.), Seed Proteins. Kluwer Academy Publishers, The Netherlands, 1999, pp. 617-633.

[6] R. Margis, E.M. Reis, V. Villeret, Structural and phylogenetic relationships among plant and animal cystatins, Arch. Biochem. Biophys. 359 (1998) 24-30.

[7] M. Martinez, I. Diaz, The origin and evolution of plant cystatins and their target cysteine proteinases indicate a complex functional relationship, BMC Evol. Biol. 8 (2008) 198.

[8] M. Martinez, M. Diaz-Mendoza, L. Carrillo, I. Diaz, Carboxy terminal extended phytocystatins are bifunctional inhibitors of papain and legumain cysteine proteinases, FEBS Lett. 581 (2007) 2914-2918.

[9] M. Pernas, R. Sánchez-Monge, L. Gómez, G. Salcedo, A chestnut seed cystatin differentially effective against cysteine proteinases from closely related pests, Plant Mol. Biol. 38 (1998) 1235-1242.

[10] F. Alvarez-Alfageme, M. Martínez, S. Pascual-Ruiz, P. Castanera, I. Diaz, F. Ortego, Effects of potato plants expressing a barley cystatin on the predatory bug Podisus maculiventris via herbivorous prey feeding on the plant, Transgenic Res. 16 (2007) 1-13.

[11] L. Carrillo, M. Martinez, F. Alvarez-Alfageme, P. Castañera, G. Smagghe, I. Diaz, F. Ortego, A barley cysteine-proteinase inhibitor reduces the performance of two aphid species in artificial diets and transgenic Arabidopsis plants, Transgenic Res. 20 (2011) 305-319.

[12] Y. Zhao, M.A. Botella, L. Subramanian, X. Niu, S.S. Nielsen, R.A. Bressan, P.M. Hasegawa, Two wound-inducible soybean cysteine proteinase inhibitors have greater insect digestive proteinase inhibitory activities than a constitutive homolog, Plant Physiol. 111 (1996) 1299-1306.

[13] C. Girard, D. Rivard, A. Kiggundu, K. Kunert, S.C. Gleddie, C. Cloutier, D. Michaud, A multicomponent, elicitor-inducible cystatin complex in tomato, Solanum lycopersicum, New Phytol. 173 (2007) 841-851.

[14] R. Gutierrez-Campos, J.A. Torres-Acosta, L.J. Saucedo-Arias, M.A. Gomez-Lim, The use of cysteine proteinase inhibitors to engineer resistance against potyviruses in transgenic tobacco plants, Nat. Biotechnol. 17 (1999) $1223-1226$.

[15] M. Martínez, E. López-Solanilla, P. Rodríguez-Palenzuela, P. Carbonero, I. Díaz, Inhibition of plant-pathogenic fungi by the barley cystatin $\mathrm{Hv}-\mathrm{CPl}$ (gene Icy) is not associated with its cysteine-proteinase inhibitory properties, Mol. PlantMicrobe Interact. 16 (2003) 876-883.

[16] S. Valdes-Rodriguez, A. Cedro-Tanda, V. Aguilar-Hernandez, E. Cortes-Onofre, A. Blanco-Labra, A. Guerrero-Rangel, Recombinant amaranth cystatin (AhCPI) inhibits the growth of phytopathogenic fungi, Plant Physiol. Biochem. 48 (2010) 469-475.

[17] Z. Abraham, M. Martinez, P. Carbonero, I. Diaz, Structural and functional diversity within the cystatin gene family of Hordeum vulgare, J. Exp. Bot. 57 (2006) 4245-4255.

[18] M. Martinez, Z. Abraham, M. Gambardella, M. Echaide, P. Carbonero, I. Diaz, The strawberry gene $C y f 1$ encodes a phytocystatin with antifungal properties, J. Exp. Bot. 56 (2005) 1821-1829.

[19] M. Pernas, E. López-Solanilla, R. Sánchez-Monge, G. Salcedo, P. RodríguezPalenzuela, Antifungal activity of a plant cystatin, Mol. Plant-Microbe Interact. 12 (1999) 624-627.

[20] A. Soares-Costa, L.M. Beltramini, O.H. Thiemann, F. Henrique-Silva, A sugarcane cystatin: recombinant expression, purification, and antifungal activity, Biochem. Biophys. Res. Commun. 296 (2002) 1194-1199.

[21] K.M. Wang, S. Kumar, Y.S. Cheng, S. Venkatagiri, A.H. Yang, K.W. Yeh, Characterization of inhibitory mechanism and antifungal activity between group-1 and group-2 phytocystatins from taro (Colocasia esculenta), FEBS J. 275 (2008) 4980-4989.

[22] S. Gourinath, N. Alam, A. Srinivasan, C. Betzel, T.P. Singh, Structure of the bifunctional inhibitor of trypsin and alpha-amylase from ragi seeds at $2.2 \mathrm{~A}$ resolution, Acta Crystallogr. D Biol. Crystallogr. 56 (2000) 287-293.

[23] J. Alfonso, F. Ortego, R. Sanchez-Monge, G. Garcia-Casado, M. Pujol, P. Castañera, G. Salcedo, Wheat and barley inhibitors active towards $\alpha$ anylase and trypsin-like activities from Spodoptera frugiperda, J. Chem. Ecol. 23 (1997) 1729-1741.

[24] O.L. Franco, D.J. Rigden, F.R. Melo, C. Bloch Jr., C.P. Silva, M.F. Grossi de Sá, Activity of wheat alpha-amylase inhibitors towards bruchid alpha-amylases and structural explanation of observed specificities, Eur. J. Biochem. 267 (2000) 2166-2173.

[25] A.M. Giudici, M.C. Regente, L. de la Canal, A potent antifungal protein from Helianthus anmuus flowers is a trypsin inhibitor, Plant Physiol. Biochem. 38 (2000) 881-888.

[26] J.Y. Kim, S.C. Park, M.H. Kim, H.T. Lim, Y. Park, K.S. Hahm, Antimicrobial activity studies on a trypsin-chymotrypsin protease inhibitor obtained from potato, Biochem. Biophys. Res. Commun. 330 (2005) 921-927.

[27] M. Lorito, R.M. Broadway, C.K. Hayes, S.L. Woo, C. Noviello, D.L. Williams, G.E. Harman, Proteinase inhibitors from plants as a novel class of fungicides, Mol. Plant-Microbe Interact. 7 (1994) 525-527.

[28] V.V. Mosolov, M.D. Loginova, N.V. Fedurkina, I.I. Benken, The biological significance of proteinase inhibitors in plants, Plant Sci. Lett. 7 (1976) $77-80$.

[29] Z.Y. Chen, R.L. Brown, A.R. Lax, T.E. Cleveland, J.S. Russin, Inhibition of plantpathogenic fungi by a corn trypsin inhibitor overexpressed in Escherichia coli, Appl. Environ. Microbiol. 65 (1999) 1320-1324.

[30] I. Cambra, F.J. Garcia, M. Martinez, Clan CD of cysteine peptidases as an example of evolutionary divergences in related protein families across plant clades, Gene 449 (2010) 59-69.

[31] M. Martínez, Z. Abraham, P. Carbonero, I. Díaz, Comparative phylogenetic analysis of cystatin gene families from Arabidopsis, rice and barley, Mol. Genet. Genomics 273 (2005) 423-432.

[32] M. Martinez, I. Cambra, L. Carrillo, M. Diaz-Mendoza, I. Diaz, Characterization of the entire cystatin gene family in barley and their target cathepsin L-like cysteine-proteases, partners in the hordein mobilization during seed germination, Plant Physiol. 151 (2009) 1531-1545.

[33] L. Carrillo, M. Martinez, K. Ramessar, I. Cambra, P. Castañera, F. Ortego, I. Diaz, Expression of a barley cystatin gene in maize enhances resistance against phytophagous mites by altering their cysteine-proteases, Plant Cell Rep 30 (2011) $101-112$.

[34] J. Alfonso-Rubi, F. Ortego, P. Castañera, P. Carbonero, I. Díaz, Transgenic expression of trypsin inhibitor CMe from barley in indica and japonica rice, confers resistance to the rice weevil Sitophilus oryzae, Transgenic Res. 12 (2003) $23-31$ 
[35] F. Altpeter, I. Diaz, H. McAuslane, K. Gaddour, P. Carbonero, I.K. Vasil, Increased insect resistance in transgenic wheat stably expressing trypsin inhibitor CMe, Mol. Breed. 5 (1999) 53-63.

[36] P. Lara, F. Ortego, E. Gonzalez-Hidalgo, P. Castañera, P. Carbonero, I. Diaz, Adaptation of Spodoptera exigua (Lepidoptera: Noctuidae) to barley trypsin inhibitor BTI-CMe expressed in transgenic tobacco, Transgenic Res. 9 (2000) $169-178$.

[37] The Magnaporthe grisea database, http://www.broadinstitute.org/annotation/ fungi/magnaporthe.

[38] The Fusarium comparative database, http://www.broadinstitute.org/annotation/ genome/fusarium_graminearum/MultiHome.html.

[39] The Dickeya dadantii 3937 genome project, http://asap.ahabs.wiscedu/asap/ query_features.php?LocationID=WIS\&GenomeID=ECH3937.

[40] The Pseudomonas syringae genome project, http://pseudomonas-syringae.org/ pst_home.html.

[41] S.K. Haq, S.M. Atif, R.H. Khan, Protein proteinase inhibitor genes in combat against insects, pests, and pathogens: natural and engineered phytoprotection, Arch. Biochem. Biophys. 431 (2004) 145-159.

[42] T.A. Valueva, V.V. Mosolov, Role of inhibitors of proteolytic enzymes in plant defense against phytopathogenic microorganisms, Biochemistry (Mosc) 69 (2004) 1305-1309

[43] U. Schlüter, M. Benchabane, A. Munger, A. Kiggundu, J. Vorster, M.C. Goulet, C. Cloutier, D. Michaud, Recombinant protease inhibitors for herbivore pest control: a multitrophic perspective, J. Exp. Bot. 61 (2010) 4169-4183.

[44] A. Kiggundu, M.C. Goulet, C. Goulet, J.F. Dubuc, D. Rivard, M. Benchabane, G. Pépin, C. van der Vyver, K. Kunert, D. Michaud, Modulating the proteinase inhibitory profile of a plant cystatin by single mutations at positively selected amino acid sites, Plant J. 48 (2006) 403-413.

[45] R. Senthilkumar, C.P. Cheng, K.W. Yeh, Genetically pyramiding proteaseinhibitor genes for dual broad-spectrum resistance against insect and phytopathogens in transgenic tobacco, Plant Biotechnol. J. 8 (2010) 65-75.

[46] J.A. Charity, P. Hughes, M.A. Anderson, D.]. Bittisnich, M. Whitecross, T.J.V. Higgins, Pest and disease protection conferred by expression of barley $\beta$ hordothionin and Nicotiana alata proteinase inhibitor genes in transgenic tobacco, Funct. Plant Biol. 32 (2005) 35-44.

[47] N.V. Khadeeva, E.Z. Kochieva, M.Y. Tcherednitchenko, E.Y. Yakovleva, K.V.Sydoruk, V.G. Bogush, Y.E. Dunaevsky, M.A. Belozersky, Use of buckwheat seed protease inhibitor gene for improvement of tobacco and potato plant resistance to biotic stress, Biochemistry (Mosc) 74 (2009) 260-267.

[48] A. Lázaro, D. Barber, G. Salcedo, E. Mendez, F. García-Olmedo, Differential effects of high-lysine mutations on the accumulation of individual members of a group of proteins encoded by a disperse multigene family in the endosperm of barley (Hordeum vulgare L.), Eur. J. Biochem. 149 (1985) 617-623.

[49] E. López-Solanilla, F. García-Olmedo, P. Rodríguez-Palenzuela, Inactivation of the sapA to sapF locus of Erwinia chrysanthemi reveals common features in plant and animal bacterial pathogenesis, Plant Cell 10 (1998) 917-924.

[50] D.C. Baulcombe, G.R. Saunders, M.W. Bevan, M.A. Mayo, B.D. Harrison, Expression of biologically active viral satellite RNA from the nuclear genome of transformed plants, Nature 321 (1986) 446-449.

[51] S.J. Clough, A.F. Bent, Floral dip: a simplified method for Agrobacteriummediated transformation of Arabidopsis thaliana, Plant J. 16 (1998) 735-743.

[52] L. Oñate-Sánchez, J. Vicente-Carbajosa, DNA-free RNA isolation protocols for Arabidopsis thaliana, including seeds and siliques, BMC Res. Notes 1 (2008) 93. 